\title{
Changing an Electrical Safety Culture - The Importance of Understanding Why
}

\section{4th Annual IEEE IAS Electrical Safety Workshop}

\author{
Richard T. Waters
}

\section{December 2015}

The INL is a

U.S. Department of Energy

National Laboratory

operated by

Battelle Energy Alliance

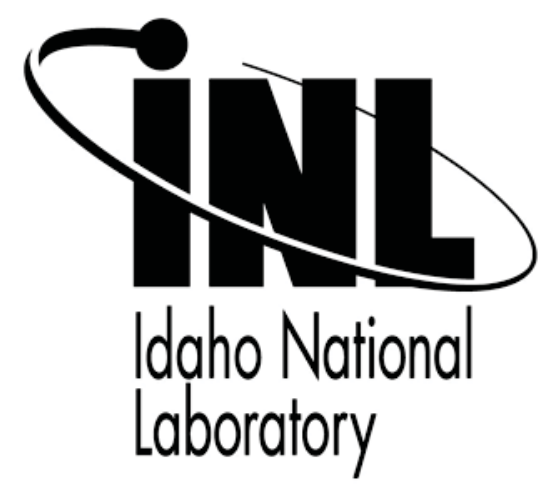

This is a preprint of a paper intended for publication in a journal or proceedings. Since changes may be made before publication, this preprint should not be cited or reproduced without permission of the author. This document was prepared as an account of work sponsored by an agency of the United States Government. Neither the United States Government nor any agency thereof, or any of their employees, makes any warranty, expressed or implied, or assumes any legal liability or responsibility for any third party's use, or the results of such use, of any information, apparatus, product or process disclosed in this report, or represents that its use by such third party would not infringe privately owned rights. The views expressed in this paper are not necessarily those of the United States Government or the sponsoring agency. 



\title{
CHANGING AN ELECTRICAL SAFETY CULTURE - THE IMPORTANCE OF UNDERSTANDING WHY
}

\author{
Richard T. Waters \\ Battelle Energy Alliance \\ Idaho National Laboratory \\ P.O. Box 1625 \\ Idaho Falls, Idaho 83415 \\ USA \\ Richard.Waters@INL.Gov
}

\begin{abstract}
Electrical workers, regardless of experience, are faced with a major barrier when first introduced to NFPA 70E, "The Standard for Electrical Safety in the Workplace," and an erroneous electrical safety culture pre-exists. This paper describes, from the author's point of view, the barrier that he and other electrical workers have experienced and his insight into overcoming the barrier. The author in conclusion will present a series of techniques that can be used to assist other electrical workers in overcoming the barrier.
\end{abstract}

Index Terms - Work Practices, Barrier, NFPA 70E, journeyman, apprentice, implementation, training, analogies.

\section{INTRODUCTION}

The implementation of NFPA 70E into a workplace presents many barriers. One significant barrier to overcome in the acceptance of NFPA 70E by electrical workers lies in answering the question, why. Electrical workers must first fully understand the reason behind implementation before they will accept and apply the standard.

\section{BACKGROUND}

\section{A. Past Work Practices}

Throughout industry, electrical workers exhibit varying degrees of education, experience, and skills. These degrees of variation can differ widely from first-year apprentices to journeymen. Electrical safe work practices can also differ widely between these same electrical workers. Electrical safe work practices in the past were not standardized and were typically passed down to the apprentice from the journeymen with whom they worked. The journeymen, in turn, learned their safe work practices from other journeymen when they themselves were apprentices and so forth. This method of transferring electrical safe work practices was filled with the potential for passing on inaccurate or incomplete electrical safe work practices with no ill intent. The journeymen simply passed down what they themselves had learned from their experience.
Because of the number of different journeymen an apprentice was likely to work with, along with the varying differences in education, experience, and skills a journeyman possessed, an apprentice was likely to have received safe work practices that were neither consistent nor standardized. An apprentice, having learned potentially poor work practices and continuing these practices after becoming a journeyman, places themselves and future generations of apprentices at risk.

\section{B. Present Work Practices}

NFPA 70E has become a recognized standard for electrical safety. It is steadily replacing the inconsistent, non-standardized method of transferring electrical safe work practices by journeymen. Apprentices today are introduced to NFPA 70E during their apprenticeship education and are instructed in the use of electrical safe work practices while in pursuit of becoming licensed electricians. Instruction on electrical safe work practices during the apprenticeship stage is currently changing the electrical safety culture of future electricians. The present method of transferring electrical safe work practices still faces opposition from both legacy journeymen electricians and employers who have yet to accept, or who have opted not to embrace, the use of NFPA 70E.

Legacy electricians can be set in their ways and resistant to change while continuing to use the old methods of transferring electrical safe work practices. Employers can also undermine the learned electrical safe work practices of apprentices. They do this by using their leverage as employers to persuade or coerce employees to ignore these safe work practices as unnecessary or costly.

Some legacy electricians have never been introduced to NFPA 70E, while others may have been exposed but are reluctant or resistant to change their ways. Their reliance on past practices and unwillingness to accept NFPA 70E can then affect the safe work practices of the apprentices assigned to 
work with them. Employers, on the other hand, may refuse to adopt NFPA 70E entirely and possibly threaten employees who seek to bring it into the workplace. It is difficult for any apprentice to do or act contrary to what an employer or journeyman tells them regardless of what they have been taught during their apprenticeship education. Most apprentices, and even journeymen, will opt to continue working in unsafe conditions for several reasons. These include peer pressure, fear of losing their job, or because they don't believe they are in a position to effect change. The fear of retribution by a journeyman or employer tends to carry a lot of influence.

\section{Future Work Practices}

The future of electrical safe work practices is extremely promising. NFPA 70E is being emphasized to a greater extent in apprenticeship programs across the country. Legacy electrical journeymen are slowly but gradually accepting and using the safe work practices of NFPA 70E, while those that remain reluctant or resistant to the changes will eventually leave the workforce through attrition.

Employers have also begun to embrace the safe work practices of NFPA 70E at an increasing rate. However, something must be done in the meantime to bring about a culture change within the ranks of current journeymen electricians. Changing the safety culture of journeymen and employers will further help reinforce the safety culture apprentices are being taught.

Failure to acknowledge and effect change in these areas will extend the time it takes to achieve a complete transformation between past work practices and the safe work practices of NFPA 70E. Employers who choose not to implement NFPA $70 \mathrm{E}$ will then have to face opposition, not only from the apprentice, but also from journeymen. A united safety stance between journeymen and apprentices may have the desired effect of forcing non-compliant or resistant employers to implement NFPA 70E.

\section{IDENTIFYING THE BARRIER}

\section{A. The Barrier}

Changing the electrical safety culture of a legacy journeyman electrician is problematic. This is due to the existence of deep rooted and likely erroneous electrical safety cultures that were obtained through years of experience. Their past successes using safe work practices handed down from other journeymen have lead them to believe that they have been working safely and are being adequately protected from the hazards of electrical energy. The longer electricians have been in the trade, the more likely it is for them to have this barrier causing them to be reluctant or resistant to the implementation of NFPA $70 \mathrm{E}$.

The skepticism of a legacy journeyman electrician towards NFPA 70E can carry a lot of weight and influence others, especially apprentices. Their skepticism is based on the belief that they have always worked safely so there's no need to change. This assumption, in part, may be due to the fact that they have never witnessed or been involved in a situation where someone has been significantly injured by electrical energy. If this mindset exists when NFPA 70E is introduced, then it is extremely important to emphasize and answer the question "WHY." If workers believe they are already working safely, then they are prone to believe that NFPA 70E is not necessary.

\section{B. The Question}

When facing this situation, a foundation must be laid that will help answer the following question: "How can a journeyman electrician be persuaded to exchange their past safety culture to one that provides them with a higher level of personal protection?"

\section{The Answer}

The answer lies in helping them understand the importance of "WHY." It is not enough for an employer to adopt NFPA 70E. It is not enough to require NFPA 70E's use through high level company documents. It is not enough to implement NFPA 70E into electrical safety programs. It is not enough to incorporate the practices in work control processes and procedures. None of these alone or in conjunction will convince a reluctant or resistant journeyman electrician to change their culture. In fact, it may have the opposite effect.

Legacy journeymen electricians believe and rely on what they have learned through years of experience. Some of that learning took place during their apprenticeship; however, the vast majority of what they learned was while working on the front line exposed to electrical hazards on an almost daily basis. They are very confident in what they know and they believe they are performing work safely based on their education and experience. If they, like many electricians, were lucky enough to have avoided injury from shock or arc flash or have never witnessed a severe shock or arc flash, then the introduction of NFPA 70E into their workplace will not be readily accepted. In this case, their experience has taught them that they have worked safely and that accidents always happen to the other guy. This creates a very dangerous barrier that, if left in place, will delay or extend the acceptance period of NFPA 70E by those who the standard was intended to protect. 
Not all electrical workers have personally seen death or severe injury caused by electrical energy, but statistics clearly show that electrical energy is one of the leading causes of death in the workplace. The statistics alone should raise concerns among electricians, but even that is not enough to persuade them to change their perspective on electrical safe work practices.

\section{LAYING THE FOUNDATION}

The key to implementing NFPA 70E deep down into an employer's electrical safety program depends upon satisfactorily answering the question of why. The importance of understanding "WHY" cannot be emphasized enough because the answer will become the cornerstone of your electrical safety program foundation. Answering the question "WHY" successfully will help to establish a strong and lasting foundation on which the entire electrical safety program can be built. If the question goes unanswered or skepticism remains among electrical workers because the question "WHY" has not satisfactorily been answered, then implementation of NFPA $70 \mathrm{E}$ into the workplace will be severely hampered.

\section{FACING OPPOSITION}

When initially exposed to NFPA 70E, legacy journeymen electricians are likely to view its implementation as a personal attack or just another employer safety program like all the others before. They tend to believe that the reason for implementation is due to the employer's perception that they are not safe workers. They may also believe that NFPA 70E will simply fade away over time like all the other short-lived safety programs before.

In an atmosphere where no significant injuries or deaths have occurred from electrical energy, they fail to understand the intent of the employer and the purpose of NFPA 70E. Many electricians in this situation will contend that the standard is unnecessary. They will often complain that it is overly burdensome, and wonder "WHY" after all these years of working safely, they suddenly have to change.

Seemingly overnight the "breaking the plane" safe work practice becomes obsolete, approach boundaries for shock appear, and arc flash is now a major concern. Personal protective equipment (PPE) instantly goes from safety glasses and leather gloves or voltage-rated gloves to wearing arc-rated, flame-resistant clothing along with the voltage-rated PPE. Electrical equipment they have interacted safely with for years now becomes a deadly monster, and the effect can be overwhelming and almost laughable. One day the safe work practices you've picked up over your career are no longer accepted or valid, and all the things you've been taught have been replaced with NFPA 70E. This can create a breeding ground for mistrust, leading to rebellion against NFPA 70E and the employer.

\section{THE QUESTION, “WHY?”}

Implementation of NFPA 70E is the right thing for an employer to do in order to protect its workers from the hazards of electrical energy. Implementation of NFPA 70E will progress rapidly and meet less resistance if the question "WHY" is effectively answered in the beginning. Electrical workers from the start of implementation must be assured that the change is not based on their prior work performance, and that it's not just a new temporary safety program. In fact, it's not new at all. They must also be made aware that the change is being made due to an improved understanding of the hazards of electrical energy.

Electrical energy itself has not changed; however, our understanding of the hazards has changed vastly over the past 20 years. They must begin to realize that our better understanding of electrical hazards has revealed that electrical workers for years have not been adequately protected from all electrical hazards. Electrical workers want nothing more than to go home safely to their families at the end of the day without injury. Employers must help them to see that NFPA 70E is based on a greater understanding of electrical hazards and provides improved protection methods. Plus, when applied properly, it will ensure that they do go home safely at the end of the day. When this is accomplished, it ultimately benefits both the employer and the employee.

\section{SPREADING THE WORD}

Any employer who intends on implementing NFPA 70E into their workplace must do so at all levels, beginning with the highest levels of management and continuing down to those that are directly affected by its implementation. Part of the implementation process involves training electrical workers in the purpose and application of NFPA 70E. It is recommended that the person or persons delivering the training fully understand the importance of "WHY." It is extremely difficult to persuade others to accept and use NFPA 70E if the instructor does not fully understand and support the standard. The instructors must believe in the implementation and be able to defend its use against an onslaught of criticism and negativity that may be fueled by previous electrical safety cultures that have been in place for years.

It is important that electrical instructors be able to establish their credibility among those they intend to instruct. It is recommended that electrical instructors have a strong electrical background. They should have a good working relationship with those being instructed where trust has already been established or can be easily established. Instructors that do not 
have an electrical background, or those who don't have a vested interest in the safety of electrical workers, will lack credibility and should be avoided. The best instructors for electrical safety are often found within the electricians themselves. Electricians can be readily made into good instructors, but it's extremely difficult to take a good instructor and make them an electrician.

Trust is a key ingredient in helping legacy journeymen electricians overcome the "WHY" barrier, and instructors taken from the ranks of those they intend to instruct helps to establish trust and credibility. Once trust and credibility are established, an instructor who understands "WHY" the safe work practices of NFPA 70E are necessary will be able to communicate those reasons effectively. Having credibility and the trust of the electrical workers and effectively communicating the reason "WHY" NFPA 70E is being implemented can still present problems. Legacy electricians - even when made aware of the hazards - and shown the statistics of electrical injury and death, and the benefits of using NFPA 70E, can still be resistant to change.

\section{TRAINING ON "WHY"}

Electrical workers will have many questions during the implementation phase and those questions need to be satisfactorily answered. Most of the questions can be answered by simply providing the facts about shock, arc flash, and blast. One would think that journeymen electricians would know the facts concerning shock, arc flash, and blast, but the reality is there are many who have not been given the facts as we know them today. In a sense, they have an outdated and potentially hazardous perception of the hazards of electrical energy.

Electrical workers will not understand "WHY" implementation of NFPA 70E is important until they have been updated completely on the facts and affects that electrical energy can have on them. Journeymen electricians typically believe that they understand the hazards of electrical shock and electrocution, but may have an incomplete picture of just how hazardous shock can be. It is a common misconception among the public and some journeymen electricians that $120 \mathrm{Vac}$ is not hazardous. This perception has evolved over time and has persisted mainly because most of us can claim to being shocked by 120 Vac on more than one occasion with no perceived injury. Most have seen arcs, but only a few may be aware of the arc-flash hazard, let alone the blast capability. Even legacy journeymen electricians may need to be reeducated about shock, arc, and blast. They must be made to understand that their current knowledge of electrical hazards may be dangerously incomplete.
During the implementation phase of NFPA 70E, training plays a vital role in helping journeymen overcome the "WHY" barrier. Statistical evidence can be used to illustrate the frequency of occurrence among electrical workers. Pictures and videos of accident scenes and injuries, as well as eyewitness accounts further illustrate and authenticate the power of electrical energy. Lessons learned from electrical accidents will serve to highlight where and how electrical events occur in the workplace by providing real-world accounts and mitigations to prevent reoccurrence. All of these things working together provide powerful evidence for the implementation of NFPA 70E and the benefits of wearing proper PPE.

Arc flash is possibly the most difficult of the electrical hazards to address during training. Statistics clearly show that arc flash is occurring, but its occurrence is fairly rare and many electricians have never experienced or witnessed the arc-flash phenomenon. Under these circumstances, it's very difficult to convince a journeyman electrician that it is a credible hazard. It's possible for an electrician to work their whole career and never experience an arc flash. This situation and the rare occurrence of arc flash can make it difficult to convince a skeptical electrician.

NFPA 70E defines arc flash as a dangerous condition associated with the possible release of energy caused by an electric arc. The very word, "possible," indicates that arc flash can occur, but it also implies (and research has shown) that arc flash may not always occur as a result of an arc. Arc flash is much more likely to occur at voltages greater than 1000 Vac, but below $1000 \mathrm{Vac}$, it is much less frequent and less predictable. Also, it's possible that an arc flash may not occur at all.

Generally, electricians have a greater respect for higher voltages above $480 \mathrm{Vac}$. This is because they interact with them less frequently, and their perception of the hazards is greater but only in regard for the higher voltage. Their perception of a higher hazard at voltages greater than $480 \mathrm{Vac}$ is correct, but the reason for their perception may be incomplete. The shock potential is greater, and contact is not always needed for the shock to occur, but the arc-flash hazard potential is also greater and more likely.

The word, possible, in the NFPA 70E definition presents a unique problem. How does an instructor convince a skeptical journeyman electrician of an arc-flash hazard when NFPA 70E only deems it possible? A skilled instructor can employ the use of analogies to counteract the inherent weakness surrounding the word, possible, to convey the seriousness behind the word. Examples of analogies that instructors could use include the following: 
- $\quad$ Safety glasses are worn not because of expected flying objects, but because it is possible.

- Hard hats are worn not because of an expected impact to the head, but because it is possible.

- $\quad$ Putting on a seatbelt when entering an automobile is not done because an accident is expected, but it is possible.

- $\quad$ Along the same lines, arc-flash protective clothing is worn not because arc flash is expected to occur, but because it is possible.

If it were possible to predict when PPE would be needed, there would be no reason to protect workers from the possibility of injury until that time. The use of analogies that are more familiar to a student may have a greater impact on helping them understand "WHY?" As an example, in the Rocky Mountain States, archery hunting is a popular sport, but it's not exempt from hazards. Archery hunters may have to contend with hazards in the form of grizzly bears or wolves. The tracks and other physical indications of activity are evidence that they may be present in the area. Accounts of bear attacks as well as numerous bear sightings also serve to warn archery hunters of the hazards every year.

Even with all the evidence pointing to their existence in the hunting area, it is extremely rare for an archery hunter to see a grizzly bear, let alone be attacked by one. Arc flash in the workplace can be easily compared to a grizzly bear encounter in the Rocky Mountain States. They are both rare occurrences, but both are possible. Well prepared archery hunters will not leave their camps without proper PPE, even if they have never seen a grizzly bear in the wild. Strapping on pepper spray or lead spray (gun) is almost second nature like putting on a seatbelt. Having this vital PPE gives them a measure of protection from a hazard that is unlikely, but possible. Wearing arc-flash PPE is very similar in that the PPE provides a measure of protection for a hazard that is unlikely, but possible. The consequences of not preparing for the possible may be a life-or-death decision and one that should not be taken lightly.

\section{CONCLUSION}

Although the future of electrical safety is bright and electrical safe work practices and cultures are constantly improving, the progress will continue to be slowed by those who do not understand the reason "WHY" implementation of NFPA 70E is so important. Electrical hazards in the workplace have not changed, but our understanding of those hazards has changed. Effectively communicating that understanding to legacy journeymen electricians will ultimately help them to realize that their past safe work practices are inadequate to protect them from electrical hazards. Employers must continue the positive trend of implementing NFPA 70E until every employer is using NFPA 70E to protect its employees.
Competent and credible electrical safety instructors must be established, and they must be able to defend NFPA 70E's implementation. Once established, instructors are then able to provide instruction on the facts surrounding shock, arc flash, and blast and the benefits of wearing proper PPE for electrical hazards. Additionally, they can employ the use of statistics, pictures, videos, eyewitness accounts, lessons learned, and familiar analogies in an effort to help legacy journeymen electricians remove barriers that have been in place for years so that they can begin to understand the importance of "WHY"

\section{VITA}

Richard Waters earned an Associate of Applied Sciences Degree from Idaho State University in 1987. Mr. Waters has accumulated 28 years as an electrician, with 8 of those spent instructing electricians and linemen in regulatory required electrical safety. He is employed with Battelle Energy Alliance at Idaho National Laboratory where he began as an electrician. He served for 17 years before accepting the electrical safety training position. Prior to his employment at INL, he served 6 years as an electrician for FMC Corporation. He currently serves as BEA's Electrical Safety Committee Chairman and Vice-Chair of the Department of Energy's Energy Facilities Contractor Operating Group (EFCOG) electrical safety task group. 